\title{
Are diurnal time-budgets and activity patterns density-dependent in the Shelduck (Tadorna tadorna) wintering in Algeria? An analysis across multiple temporal scales
}

Djamel Bensizerara ${ }^{1}$ (I) and Haroun Chenchouni ${ }^{2,3^{*}}$ (1)

\begin{abstract}
Background: The Shelduck (Tadorna tadorna) is a characteristic waterbird species of inland wetlands in northeastern Algeria. Its wintering behavior in relation to changes of local abundances and foraging group density is poorly known.

Objectives: This study aims at monitoring patterns of diurnal activities and the variation of behavioral time-budgets in relation to numbers of wintering Shelducks. We investigate temporal variations of diurnal activities across multipletime scales and consider their interrelationships.
\end{abstract}

Methods: Assessments of local population abundance were weekly surveyed during two wintering seasons (20102012), whereas diurnal activities (feeding, sleeping, swimming, preening, loafing, flying, courtship, and antagonism) were studied three times a month during seven hours (08:00-16:00) using the Scan method. Time budget variations of each behavioral activity were tested using nested ANOVAs following multiple time scales. Generalized linear mixedeffects models (GLMM) tested whether variations in diurnal activities were density-dependent.

Results: During the wintering season, Shelduck's numbers followed a bell-shaped trend, which indicated that the species was typically a wintering migrant in Sabkha Djendli. The first individuals arrived onsite in October-November then numbers reached a peak in January (up to 2400 individuals in 2012) with steady density during December-February, afterward individuals left the site progressively until late April when the site is deserted. During both wintering seasons, diurnal activities were dominated by feeding (60\%), followed by sleeping (12\%) then swimming and preening with $9 \%$ and $8 \%$, respectively. The rest of the activities (loafing, flying, courtship and antagonistic behaviors) had low proportions of time budget. ANOVAs showed that activity time budgets varied significantly following multiple time scales (year, season, month, day, semi-hour). Time budgets of diurnal activities during each wintering season were significantly interrelated. Correlations patterns between the two seasons were similar. GLMMs revealed that the variations of diurnal activities were not density-dependent, except for preening and swimming.

Conclusion: During the wintering season, habitats of Sabkha Djendli are important for waterbirds, including the Shelduck that used the lake mainly for food-foraging and resting. The 2400 individuals censused in mid-winter are important locally and at the North African scale. This stresses the need to strengthen the protection status of this wetland and mitigate degradation sources that threaten wintering waterfowl.

Keywords: Anatidae, Multi-temporal scales, North African wetlands, Time budget, Waterbird census

\footnotetext{
*Correspondence: chenchouni@gmail.com

${ }^{2}$ Department of Natural and Life Sciences, Faculty of Exact Sciences and Natural and Life Sciences, University of Tebessa, 12002 Tebessa,

Algeria

Full list of author information is available at the end of the article
} 


\section{Background}

Wetland ecosystems are an integral part of the regional natural heritage, as they form important habitats for a specialized and well-adapted flora and fauna. But the increasing anthropogenic pressures, combined with the effects of global climate change, have contributed to reducing submerged areas and loss of biodiversity and ecosystem functions of these highly productive but fragile habitats (Öztürk et al. 2011; Finlayson et al. 2018). Ecologically, wetlands play critical roles specifically for waterbirds as breeding, foraging, wintering and flyway areas (Tamisier and Dehorter 1999; Samraoui and Samraoui 2008).

For the conservation of waterbirds, Wetlands International (2012) conducted population estimates to determine the increase, stability or decrease trends of waterbird populations at flyways. Conservation biology has evolved over time while focusing on habitat management and identification of target species as well as monitoring their ecology and population dynamics to detect potential ecosystem disturbances (Chenchouni 2010c; Finlayson et al. 2018). In Africa and Western Eurasia, Wetlands International is monitoring populations of over 60 species of Anatidae to estimate population size and delineate their biogeographic range boundaries (Delany and Scott 2002).

The ecology of waterbirds has been extensively studied in European and Nearctic wetlands (Tamisier and Dehorter 1999; Delany and Scott 2002; Baldassarre and Bolen 2006; Geraci et al. 2012; Jensen et al. 2016), but this subject presents several scientific gaps in the Mediterranean area and in particular North African wetlands. Neglecting a biogeographic region/area in wetland-based waterbird conservation programs may fail to achieve a comprehensive conservation scheme due to the migratory ecology of several species. Thus, the success of a conservation strategy implies that migration, wintering, breeding, staging and stopover habitats should be taken into account in conservation planning and actions (Sayoud et al. 2017; Bezzalla et al. 2018; Finlayson et al. 2018).

Wildfowl Anatidae are the main species of waterbirds that use North African wetlands, especially Algeria, for wintering and reproduction (Samraoui and Samraoui 2008; Sayoud et al. 2017). Several studies have surveyed the behavior of Anatidae in Algerian wetlands (Boulkhssaim et al. 2006; Houhamdi and Samraoui 2001, 2008; Bouchaala et al. 2017). However, beyond the description of time budgets of bird activities, nothing has been done to explain ecologically behavioral changes and habitat use nor the environmental factors influencing the observed activity patterns. It is therefore imperative to know how these species use the habitat during wintering, what are the environmental factors that determine the modalities of habitat use, and how these species adjust their behavior in order to efficiently take advantage of habitat services to match their ecological needs that vary in space and time (Paracuellos 2006; Cherkaoui et al. 2017).

Algeria has successfully classified 50 wetlands as Ramsar sites, of which 13 sites are located in the Hauts Plateaux region in northeastern of the country (Balla 2012). These continental wetlands are recognized for their exceptional environmental properties in terms of hydrogeology and soil/water salinity since the majority of sites are classified as Sabkhas or Chotts (syn. salt lakes or playas), with high ecological and socio-economic values as they shelter diverse plant and animal communities (Öztürk et al. 2011; Aliat et al. 2016; Bezzalla et al. 2019a). Djendli Sabkha is part of the Oum-El-Bouaghi wetland complex in northeastern Algeria. The site represents a reservoir of both plant and animal biodiversity (Bensizerara et al. 2013; Neffar et al. 2016; Chenchouni et al. 2015; Chenchouni 2017b), but which remains very little studied except for the census of wintering waterbirds (Chenchouni 2007; Bensizerara 2014). The site has multiple ecological services attributed mainly to the high carrying capacity of a large variety of waterbirds, especially the Shelduck (Tadorna tadorna) and the Greater Flamingo (Phoenicopterus roseus), which move through the two shores of the Mediterranean Sea (Delany and Scott 2002; Geraci et al. 2012), namely the populations of northwestern Europe (Walmsley 1986), and the wintering populations in North Africa, Algeria in particular (Ledant et al. 1981; Isenmann and Moali 2000; Sayoud et al. 2017). For example, waterbird census in winter 2005 in the Oum-El-Bouaghi wetland complex showed that Shelduck's population was much larger than the population sizes previously recorded in all Algeria, where it reached a total of 68,000 individuals (Boulkhssaim 2008).

This study aims at determining the seasonal abundance of Shelducks wintering in Sabkha Djendli during two wintering seasons (2010-2012). The study also seeks to clarify the ecological role of this wetland in species wintering ecology and understand its wintering strategy through a regular monitoring of diurnal foraging activities and their variations at different time scales. Investigating time budgets and habitat use has been found to be important tools in unraveling the ecological requirements of waterfowl by linking foraging activities to habitat selection (Caraco 1979; Paulus 1988; Baldassarre and Bolen 2006). This in turn provides fundamental information on the functional role of wetlands, and how habitat changes can affect the ecology of birds using the ecosystem (Tamisier and Dehorter 1999; Baldassarre and Bolen 2006; Cherkaoui et al. 2017).

The purpose of this study was to determine temporal changes in numbers of wintering Shelducks in Sabkha 
Djendli through a mathematical modelling approach. This survey aims at describing time-budget of diurnal behavioral activities and habitat use by analyzing the effect of local density on the variation in time budgets of different daytime activities. Since the exercise of certain activities is dependent on the number of individuals of the foraging group (Bezzalla et al. 2019b), our assumption is to observe some behaviors such as feeding, sleeping and preening, positively correlated with large group sizes. We assume that vigilance increases with the increase of abundances of conspecifics and/or relatives, therefore, foraging activities are expected to be positively correlated with the density of the foraging group that benefits from this vigilance mainly to detect and avoid both terrestrial and aerial predators, or other disturbance sources. On the other hand, we hypothesize that dense foraging groups are expected to generate intra- and inter-specific competitions, which will increase courtship and antagonistic behaviors (Caraco 1979; Henriksen et al. 2015; Cherry and Barton 2017). In addition to the density-dependence of bird activities, whether conditions may shape patterns of these activities (Bezzalla et al. 2019b). Finally, this study seeks to bring new and additional knowledge to already existing data on the ecology of the species, in order to better guide conservation programs and planning actions in Algerian and North African wetlands.

\section{Methods \\ Study area}

Sabkha Djendli $\left(35^{\circ} 35^{\prime} \mathrm{N}\right.$ to $35^{\circ} 46^{\prime} \mathrm{N}$; $06^{\circ} 20^{\prime} \mathrm{E}$ to $06^{\circ} 35^{\prime} \mathrm{E}$ ), is a natural, salt, temporary wetland, located $46 \mathrm{~km}$ in the north-east of the chief town of the Wilaya "Province" of Batna (Fig. 1). It extends mainly on the territory of the municipality of Boumia in northeastern Algeria (Bensizerara et al. 2013). Sabkha Djendli is surrounded by three mountain ranges and overlooks the plains of Boulhilet. The waterbody is fed by the hydrographic network of the Chemora sub-watershed (Chenchouni 2007). The site covers a total area of 3700 ha with an average altitude of $833 \mathrm{~m}$ (Chenchouni et al. 2015).

Long-term meteorological data (1973-2016) showed that the Djendli region has a semi-arid Mediterranean bioclimate with cool winter. The dry season lasts 4-6 months a year (Fig. 1). The region is classified climatologically as semiarid following the classification of aridity index (ratio of annual precipitation to annual $\mathrm{PET}=0.34)$ and De Martonne index $(=15)$. Whereas Köppen's classification indicates that the climate of the region is $\mathrm{BSk}(\mathrm{B}=$ arid climate, $\mathrm{S}=$ steppe, and $\mathrm{k}=$ cold $)$.

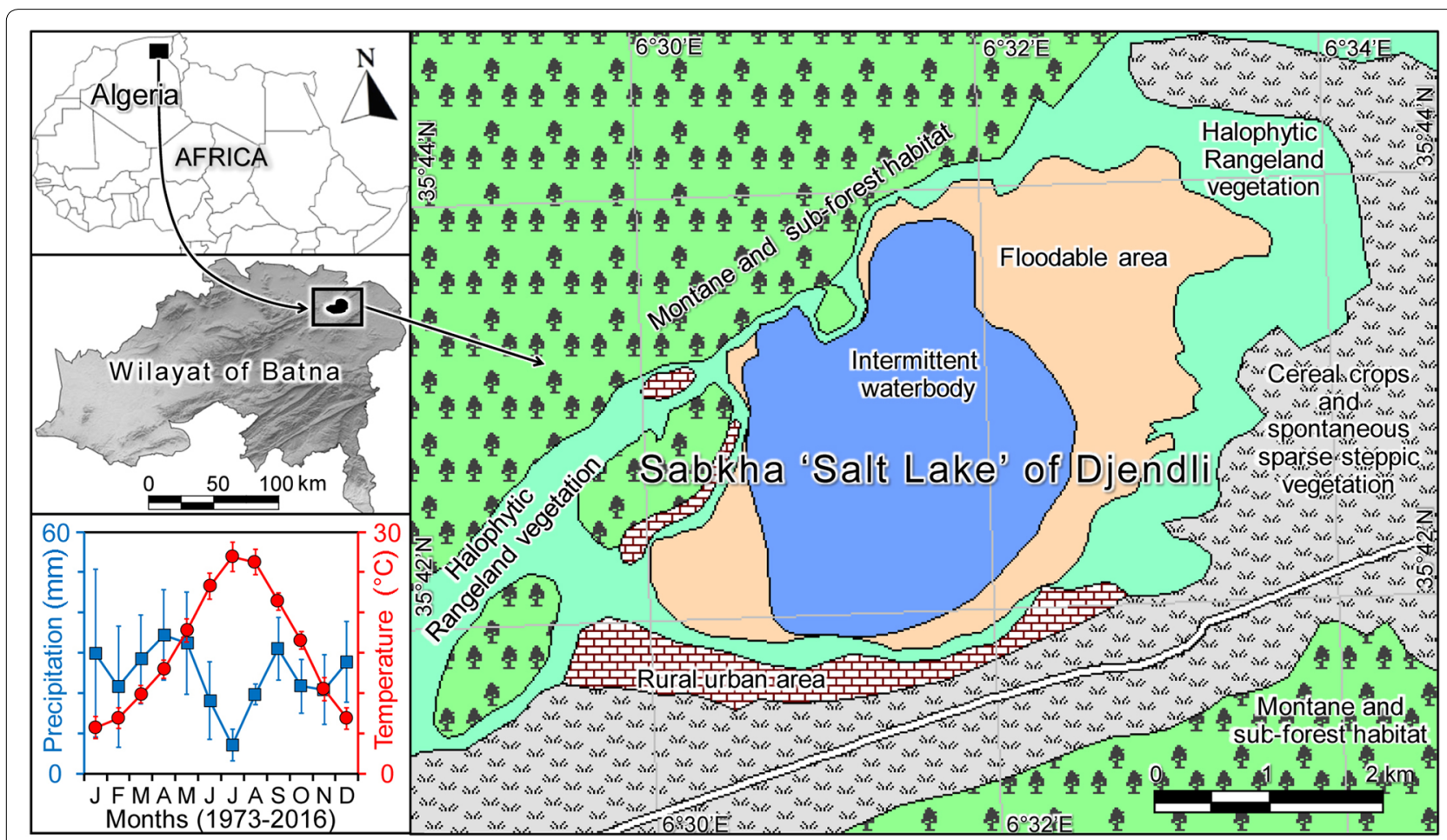

Fig. 1 Geographical location and different landscapes of Sabkha Djendli (Batna Province "Wilaya", Northeastern Algeria). The bottom-left plot represents the ombrothermic diagram of Gaussen and Bagnouls of the study region (1973-2016), with values of precipitation and temperature are monthly averages 
The coldest month is January with average temperature equals $5.3 \pm 1.1{ }^{\circ} \mathrm{C}$, and the hottest month is July with $22.8 \pm 2.4{ }^{\circ} \mathrm{C}$. The climate undergoes important of interand intra-year fluctuations mainly the amount of rainfall that have a marked irregularity. The average annual rainfall is $208.5 \pm 96.7 \mathrm{~mm}$ per year with the most rained month in January $(51.6 \pm 24.7 \mathrm{~mm})$ and the driest month in July $(9.3 \pm 3.1 \mathrm{~mm})$ (Additional file 1: Tables S1 and S2).

Sabkha Djendli is diversified in terms of landscape habitats with various physicochemical characteristics of water and soil, which play a key role in the development of a specific flora, such as Atriplex spp., Salsola spp., Salicornia spp., Arthrocnemum spp. (Neffar et al. 2016; Chenchouni 2017b). The site is frequented each winter by migratory birds of various species such as Anatidae and Charadriiformes (Chenchouni 2007; Bensizerara 2014).

\section{Bird census techniques}

Weekly counts of Shelducks wintering at Sabkha Djendli were conducted from fixed observation points during two wintering seasons (from September 2010 to April 2012). A telescope $(25 \times 60)$ and a binocular $(10 \times 25)$ were used for observation and counting of individuals. During counts that lasted from 08:00 to 10:00, individual counts were applied whenever the Shelduck group is at a distance of less than $200 \mathrm{~m}$ and the abundance does not exceed 200 individuals. However, when the number of individuals is greater than 200 individuals or if the group of birds is distant (i.e. $>200 \mathrm{~m}$ ), the quantitative estimate is made by dividing the visual field into several bands, then the number of birds in an average band is counted and reported as many times as bands (Bibby et al. 1998; Chenchouni 2010a).

\section{Behavioral study techniques}

The daytime behavior of Shelduck was studied each year during the period December-April, three times a month, with continuous observations from 08:00 to 16:00. Thus the study encompassed 30 surveys and totaled $210 \mathrm{~h}$ of monitoring for the two wintering seasons 2010-2011 and 2011-2012. Shelduck's activities were surveyed using the Scan method (Bezzalla et al. 2019b), which consists of observing and recording the instant activities of a group of conspecifics ( $>200$ individuals) for $10 \mathrm{~min}$ by dividing its behavior into eight activities: feeding, sleeping, swimming, preening, loafing, flying, courtship and antagonistic behaviors. A minimum of 12 individuals was surveyed and screened for their activities in order to avoid re-sampling and/or the loss of the targeted individuals being focused on due to their flying or not being clearly visible (Tamisier and Dehorter 1999; Houhamdi and Samraoui 2008).

\section{Statistical analysis Modelling temporal changes of wintering numbers}

As most of inland wetlands in North Africa receive waterbirds from mid-autumn to mid-spring, with the maximum of numbers reaching in winter (changes in numbers displayed a typical humped or bell-shaped curve), the temporal variation of local abundances of the Shelduck during the wintering seasons 2010-2012 was analyzed using a non-linear modelling approach. First data of the two wintering seasons were averaged for each survey (every 10 days per month). Then, using the $\mathrm{R}$ package \{mgcv\} (R Core Team 2018), the dataset obtained was tested using a generalized additive model (GAM) with a smooth function of time '10-day period. GAM is particularly useful because it is non-parametric smoother to the data without requiring to specify any particular mathematical model to describe the non-linearity (Crawley 2013). Nevertheless, concrete parametric mathematical models are often needed to enable computations and predictions in numerical applications (Chenchouni 2017a). Accordingly, the data was tested with the positive-negative Richards model (double-Richards) using the R package \{FlexParamCurve\} (Oswald et al. 2012). This package uses the self-starting function (SSposnegRichards) that combines the two curves of Richards. The complete Double-Richards model included eight parameters (Eq. 1):

$$
\begin{aligned}
N= & A s y m /[1+M \exp (-K(t-\text { Infl }))] / M \\
& +R A s y m /[1+R M \exp (-R k(t-R i))] / R M
\end{aligned}
$$

where $N$ is the number of individuals; $t$ is time '10-day periods'; Asym, $K$, Infl and $M$ are the asymptote, rate parameter, point of inflection, shape parameter of the positive (increasing) curve of Richards; and RAsym, $R k$, $R i$ and $R M$ are the corresponding parameters for the negative (decreasing) curve.

Although this package provides a series of self-starting functions for monotonic and non-monotonic curves of the Richards model, it was applied in this study only to model two bi-sigmoidal trajectories, viz. a five-parameter bi-logistic curve and a six-parameter model (doublelogistic/double-Gompertz/double-Von Bertalanfy) (see Oswald et al. 2012: Model No 24 and 22, respectively). The Akaike information criterion (AIC) value was calculated for each model (GAM, five- and six-parameter Double-Richards models) to select the one with the best fit.

\section{Variations of diurnal time-budget of behavioral activities}

Based on the contingency table summarizing activity time budgets for each wintering season, Pearson Chi squared test $\left(\chi^{2}\right)$ was computed to determine the 
dependency between behavioral activity patterns following of wintering seasons. Multiple ANOVAs were applied to identify how time budget of each behavioral activity vary at multiple time scales, i.e. 'year', 'season', 'month', 'day' and 'semi-hour.' Because these time variables were nested, each ANOVA included the hierarchical nested factors 'year/season/month/day/semi-hour' as well as three-level interactions in a single linear model. To test whether the variation of each diurnal activity of the Shelduck is density-dependent, generalized linear mixed-effects models (GLMM) were applied. Shelduck's local abundance was entered in each model as a fixed effect whereas month was considered as a random effect since surveys were conducted three times every month. Data analyzed were based on these surveys which were considered as pseudoreplications (Crawley 2013). Statistical analyses were carried out using the package \{nlme\} in $\mathrm{R}$ ( $\mathrm{R}$ Core Team 2018). The relationships between time budgets of diurnal activities were examined using Pearson correlation tests for each wintering season and for both seasons combined. The package \{corrplot\} in $\mathrm{R}$ was used to plot correlation matrices. Then, Mantel's two-tailed permutation test was used to investigate the similarity of correlation patterns between correlation matrices of the two wintering seasons.

\section{Results}

\section{Population assessment and temporal changes of local} abundances

The first group of Shelduck (about 250 individuals) arrived at Sabkha Djendli during mid-November for the first wintering season (2010-2011). This number increased steadily to reach up a maximum of 600 individuals in mid-December, then gradually decreased in mid-January to reach 420 individuals. During the second half of January and the month of February, the Shelduck deserted the site because of its total desiccation, then it returned in early March with a first group of about 700 individuals, to reach 900 individuals towards the end March. About 250 birds remained in mid-April and left the site at the end of the month coinciding with another drying phase of the waterbody. For the second wintering season (2011-2012), approximately 160-200 individuals were observed during the first week of October and then the number has increased steadily and continuously to reach a maximum of 2400 individuals at the mid-January, then the numbers declined gradually until the waterbody was empty by the last week of April (Fig. 2).

The simplification of the three nonlinear models testing the temporal variation of Shelduck numbers using the Akaike's information criterion indicated that the GAM held the lowest value $(\mathrm{AIC}=363.2)$ compared to five- and six-parameter Double-Richards models $(\mathrm{AIC}=368.4$ and $\mathrm{AIC}=366.1$, respectively). The GAM showed highly significant effect $(F=19.88, p<0.001)$ of smoothed term (surveys of 10-day period) with $89.2 \%$ of deviance explained (Table 1), which implies that GAM smoother fitted adequately to the bell-shaped data. This was obvious when predicted curves of all models were compared. The latter showed that the maximum of Shelduck's numbers was projected to be reached during surveys of January (Fig. 3). Both Double-Richards models showed a similar trend for the increasing curve where model parameters revealed the same patterns, with the asymptote $(A s y m)$, rate parameter $(K)$ and point of inflection (Infl) significantly different from zero $(p<0.05)$. Whereas in five-parameter Double-Richards model the asymptote (RAsym) of the decreasing curve was significantly different from zero $(t=-2.77$, $p=0.011$ ), while the point of inflection $(R i)$ of the fiveparameter model was significantly different from zero $(t=8.64, p<0.001)$. The parameters of the double-logistic model explaining the curve of temporal changes in numbers $(N)$ through 10 -day periods $(t$, with $1=1$ st decade of September; Fig. 3), were as follows: $N=\{1733.8639 /$ $([1+\exp (-0.5746 \quad(t-8.5598))])\}-\{1758.0238 /([1+$ $1.9059 \times \exp (t)] \times 1 / 1.9059)\}$ for five-parameter Double-Richards model; and $N=\{1139.0003 /([1+\exp (-$ $1.0588(t-8.0153))])\}-\{1470.3866 /([1+\exp (-0.3309$ $(t-22.0231))])\}$ for six-parameter Double-Richards model (Table 1).

\section{Diurnal activities \\ Annual pattern}

The study of the diurnal activity pattern in the Shelduck over a period of 2 years resulted in the following scheme of time budgets (Fig. 4). Feeding totaled $60 \%$ of time budget and dominated other diurnal activities, followed by sleeping $12 \%$, then by swimming and preening with $9 \%$ and $8 \%$, respectively. The rest of the activities (loafing, flying, courtship and antagonistic behavior) had low proportions. The Pearson Chi squared test $\left(\chi^{2}=0.438, \mathrm{df}=7\right.$, $p=0.999$ ) indicated that there is no dependence between patterns of time budget of activities according to the two wintering seasons.

\section{Monthly variations per year}

Feeding activity was noted from the beginning of the monitoring of diurnal activities throughout the study. Time budget allocated to this activity averaged 59\%, with high scores during December (65\%) and a minimum during January (52\%). Sleeping was too an important activity throughout the period of the study. It showed an average rate of $16 \%$ of monthly time budget, with a maximum of $19 \%$ recorded at the beginning of 


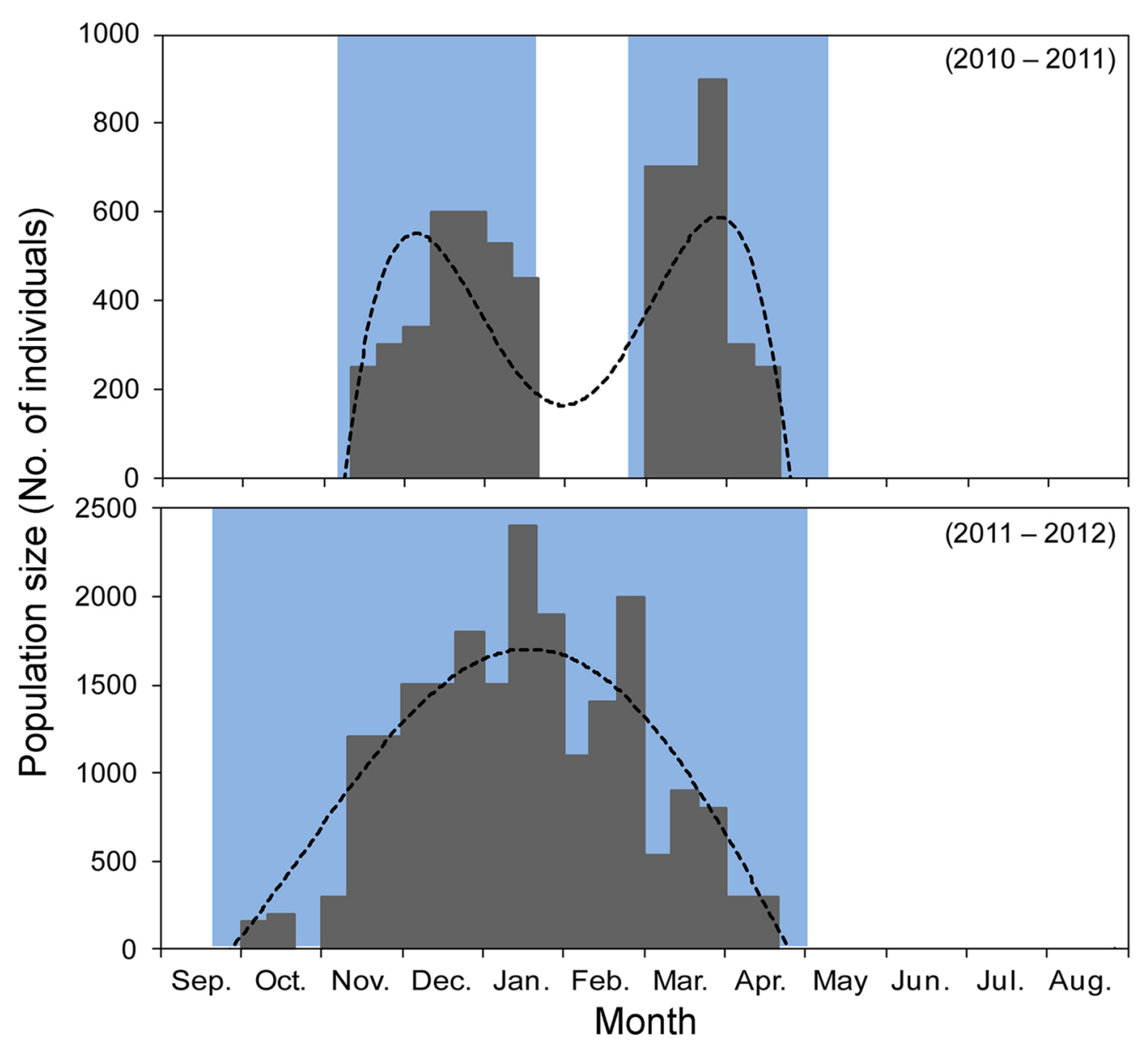

Fig. 2 Numbers of the Shelduck censused in Sabkha Djendli (northeastern Algeria) between 2010 and 2012. Solid gray represents numbers of the Shelduck, background light blue shows period when the waterbody of the Sabkha had water, and the white pattern represents a waterless site. Dotted line is a polynomial regression fitted to data

January, then the activity showed a sawtooth pattern until the end of March, when it recorded the lowest value (9\%). The Shelduck spent on average $7.52 \%$ of the time budget in swimming which was marked with a max during the second half of December (12.5\%), while the lowest value was recorded during the beginning of February (3.5\%). Loafing averaged 6\% almost throughout months of this survey.

Preening plumage averaged $8 \%$ of the time budget with a minimum of $5 \%$ noted during the last week of December and a maximum of 12.5 almost throughout the rest of the study period especially during high temperature days. Flying activity was frequent throughout the study but with low rates, and it averaged 4\%. Minimum value of time budget allocated to this activity was $2 \%$ during mid-December, and the maximum reached $7 \%$ in mid-January. Antagonistic behavior was 1\% of time budget throughout the study period. The courtship averaged $1 \%$, fluctuating between $0 \%$ in December and $4 \%$ in March (Fig. 5).

\section{Daily variations per season}

Activity time budgets showed variations during the same day. Feeding was the most dominant behavior during all the days of both seasons, whether during the winter or spring season. The max of the time budget assigned to feeding activity (74\%) was observed during the mid-day around 10:30-11:00 during winter. Time spent in sleeping was fairly constant during the day, but with a peak during the morning (25\%) which gradually decreased until the afternoon when it was noted with $19 \%$. With regard to swimming, preening, loafing and short episodes of flying were especially noted at the beginning and towards the end of the day. Courtship and antagonistic behaviors were more observed from midday (Fig. 6). 
Table 1 Summary and parameterization of nonlinear models (GAM, five- and six-parameter DoubleRichards models) testing the temporal variation of numbers of the Shelduck wintering at Sabkha Djendli in northeastern Algeria

\begin{tabular}{|c|c|c|c|c|c|}
\hline $\begin{array}{l}\text { Parametric } \\
\text { coefficients }\end{array}$ & Estimate & Std. error & $t$-value & $p$ value & Sig. \\
\hline \multicolumn{6}{|c|}{ Generalized additive model 'GAM' (AIC = 363.2) } \\
\hline Intercept & 505 & 33.26 & 15.18 & $<0.001$ & *** \\
\hline Smooth term & Edf & Ref.df & F & $p$-value & Sig. \\
\hline s(10-day period) & 6.75 & 7.86 & 19.88 & $<0.001$ & *** \\
\hline \multicolumn{6}{|c|}{ Five-parameter Double-Richards model $(\mathrm{AIC}=368.4)$} \\
\hline Asym & 1733.8639 & 557.45 & 3.11 & 0.005 & ** \\
\hline K & 0.5746 & 0.23 & 2.52 & 0.019 & * \\
\hline Infl & 8.5598 & 0.65 & 13.20 & $<0.001$ & $* * *$ \\
\hline RAsym & -1758.0238 & 635.49 & -2.77 & 0.011 & * \\
\hline $\mathrm{RM}$ & 1.9059 & 1.39 & 1.37 & 0.184 & ns \\
\hline \multicolumn{6}{|c|}{ Six-parameter Double-Richards model $(\mathrm{AIC}=366.1)$} \\
\hline Asym & 1139.0003 & 221.26 & 5.15 & $<0.001$ & $* * *$ \\
\hline K & 1.0588 & 0.51 & 2.10 & 0.048 & * \\
\hline Infl & 8.0153 & 0.51 & 15.85 & $<0.001$ & $* * *$ \\
\hline RAsym & -1470.3866 & 791.61 & -1.86 & 0.077 & ns \\
\hline $\mathrm{Rk}$ & 0.3309 & 0.25 & 1.33 & 0.197 & ns \\
\hline $\mathrm{Ri}$ & 22.0231 & 2.55 & 8.64 & $<0.001$ & $* * *$ \\
\hline
\end{tabular}

Asym, K, Infl, RAsym, RM, Rk and Ri are parameters of the positive-negative Richards model, see subsection: modelling temporal changes of wintering numbers

AIC Akaike information criterion, Sig. statistical significance

*** $p<0.001,{ }^{* *} p<0.01,{ }^{*} p \leq 0.05,{ }^{n s} p>0.05$

\section{Multi-temporal variations}

The nested ANOVAs testing the variation of activity time budgets following multiple time scales (year, season, month, day, semi-hour) showed that diurnal behaviors were not constant over time. ANOVAs revealed that time budget spent in feeding, sleeping, preening, swimming, loafing, and flying varied significantly $(p<0.05)$ between the five time factors and their interactions (Table 2). Time budget of all activities varied significantly at the scale of years except for courtship and antagonistic behavior, and the latter presented only significant differences $(p<0.001)$ between semi-hour within the day and following the interaction 'Month $\times$ Day $\times$ Semi-hour'. The variation on time expended in feeding and courtship was not statistically significant at the scale of days, whereas time budget of preening and swimming presented no significant variation at the scale of seasons.

\section{Relationships between behavioral activities}

Regardless of wintering season, time budgets were positively correlated between diurnal activities except for sleeping that was deemed negatively associated with almost all other activities (Fig. 7). Time budget allocated to feeding was correlated significantly $(p<0.05)$ with all activities expect for courtship. For both wintering season and overall, swimming and preening were significantly correlated with all other activities except for the correlations 'preening versus flying' during the season 2010-2011 and 'swimming versus sleeping' and 'preening versus sleeping' during 2011-2012. For both seasons,

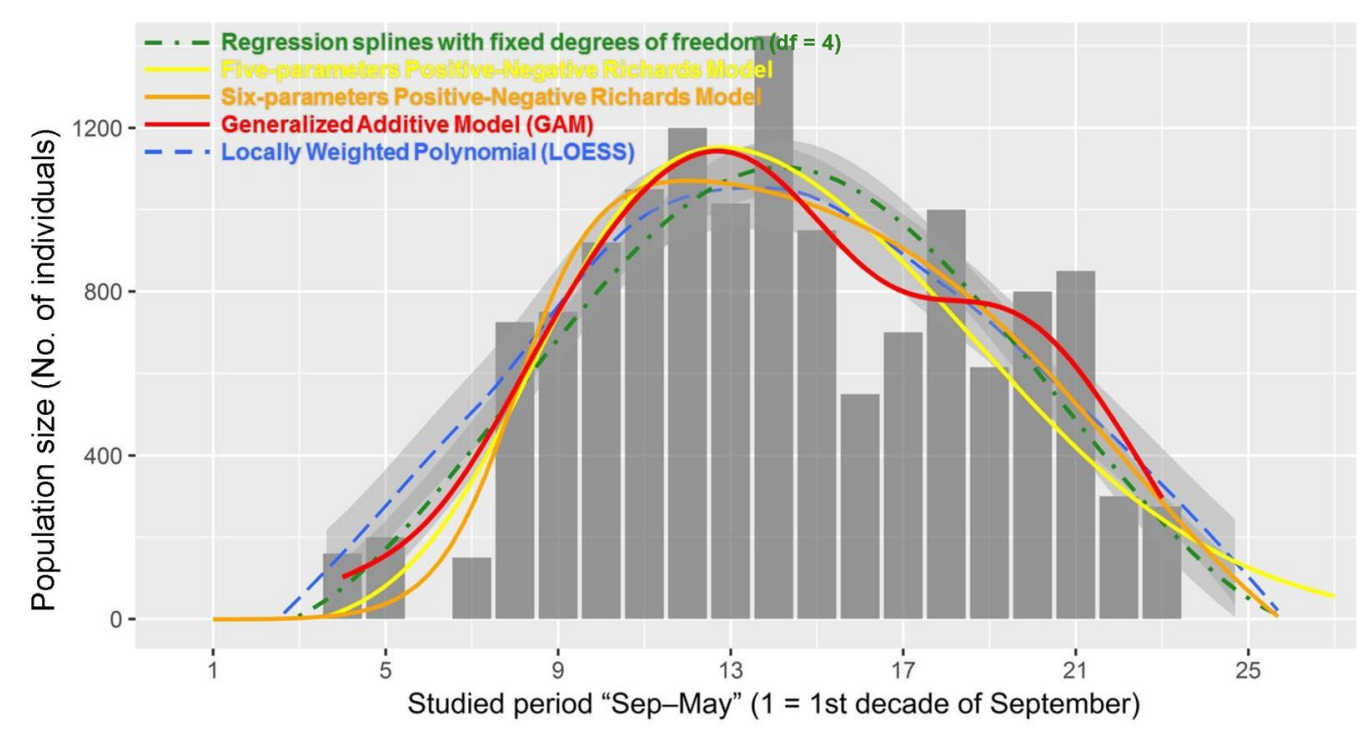

Fig. 3 Predicted curves of non-linear models testing the temporal changes in numbers of the Shelduck wintering at Sabkha Djendli (northeastern Algeria). Vertical bars represent averages of the observed data during the wintering seasons 2010-2012. The curves of LOESS and regression splines are fitted with 95\% confidence region in light grey 


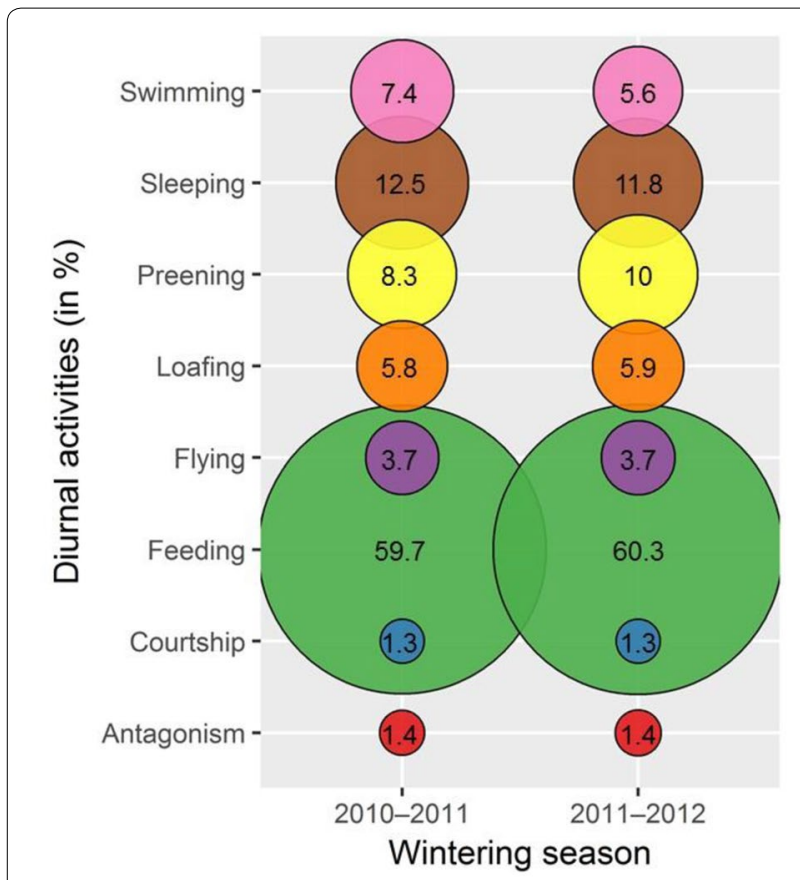

Fig. 4 Balloon plot showing proportions of the time budgets of various daytime activities of the Shelduck at Sabkha Djendli (Northeastern Algeria) during the wintering seasons 2010-2011 and 2011-2012

flying was correlated with all activities. The Mantel's permutation test revealed that even with the slight differences in correlation distribution between activities of the two wintering seasons, the overall pattern of these correlations in the two matrices was similar between years $(r=0.433, p=0.023)$.

\section{Effect of local abundance on diurnal activities}

GLMMs showed that the variation in almost all diurnal activities of the Shelduck was not dependent on the group size of the on-site population, except for preening and swimming. GLMMs indicated that Shelducks spent more time preening when the density of the group on-site was higher $(p=0.040)$. While the time spent on swimming decreased significantly $(p=0.044)$ with the increase in the number of Shelducks (Table 3, Fig. 8). This suggests that vigilant behaviors of conspecifics resulted from large group size allowed the Shelduck to afford spending more time in preening plumage. However, in dense groups swimming decreased as all Shelducks seem to be occupied in a competitive feeding behavior. Indeed, during both wintering seasons, time budgets of swimming and feeding behaviors were deemed positively correlated (Fig. 7).

\section{Discussion}

\section{Changes in local numbers}

Shelducks frequenting Sabkha Djendli are typically wintering groups since they are observed from the beginning of October and remain in the wetland until the end of April, afterward all individuals desert the site. It should be noted that the site during wintering seasons often experiences periods of waterbody desiccation during which the waterbirds, including the Shelduck, leave the site to reach the neighboring wetlands. But once the site is in water, waterbirds rejoin the waterbody again. This is the case of our study area during the 2010-2011 wintering season. Previous studies indicate that Sabkha Djendli is an important site for carrying and sheltering thousands of wintering Shelducks (Chenchouni 2007; Bensizerara 2014; Bellagoune 2015). The present study shows that the abundance of this species reached up to 2400 individuals during January 2012, with more or less stable numbers that exceed 1000 individuals for the period November-February.

During summer which coincides with the rise of the temperatures and the decrease of the precipitations combined with the hot and fast winds (Additional file 1: Fig. S1), waterbirds practically desert the site, sometimes even the wetland is in water, but obviously when it is dry. This is explained by the impoverishment of the site in food under these relatively unfavorable conditions. The birds return with the arrival of the first autumnal rains of the next wintering season (September-October). This phrenological pattern in waterbirds migratory behavior is mainly due to the seasonality of climatic factors (mainly photoperiod, temperature and precipitation), which trigger the reproduction period, and also the local environmental factors and human activities (Tamisier and Dehorter 1999; Chenchouni 2012; Jensen et al. 2016; Xu et al. 2017).

In fact, several anthropogenic disturbances directly threaten the fauna and flora of Sabkha Djendli, resulting in significantly decreasing abundances, species richness and diversity of several communities (Bensizerara 2014; Chenchouni 2007, 2017b; Chenchouni et al. 2015). Illegal hunting and overgrazing the spontaneous halophytic vegetation and steppe rangelands around the site (Fig. 1), as well as the cutting and/or firing of clumps of Juncus maritimus, Atriplex halimus and Typha angustifolia by the local residents significantly disturb birds and cause severe degradation of fragile soils (Chenchouni 2007; Bensizerara et al. 2013). Hunting is known to cause birds to change their wintering sites, or even change their distribution in their migration areas (Jensen et al. 2016). Desertification and intense drought events-increasingly frequent and long-affecting the region during the last decades, cause severe stress for flora and fauna (Benabderrahmane and Chenchouni 2010; Chenchouni 2010b). 


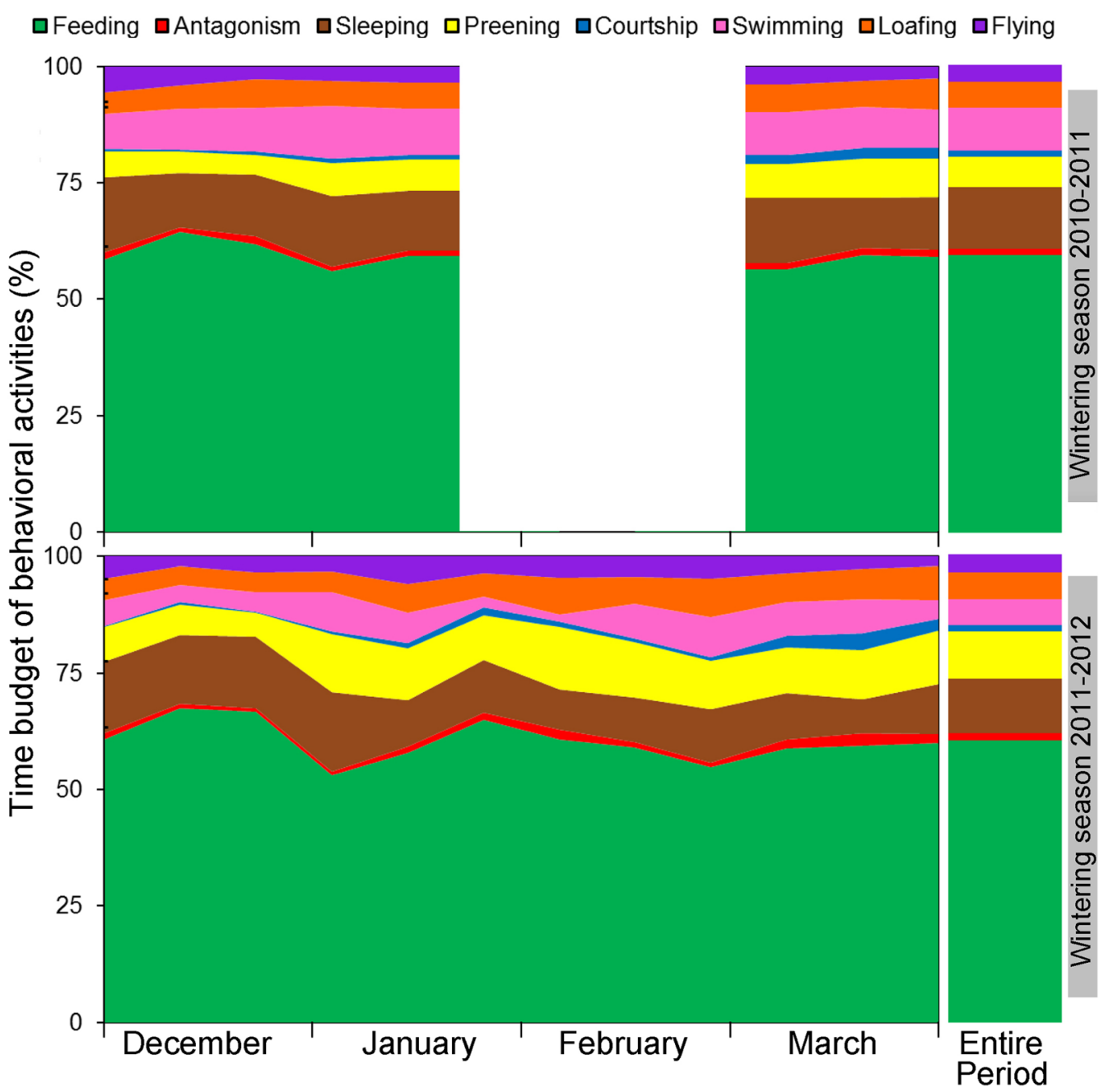

Fig. 5 Monthly variation in time budgets of daytime activities of the Shelduck during the two wintering seasons 2010-2011 and 2011-2012 at Sabkha Djendli (Northeastern Algeria)

The arrival of migratory bird populations, in this case ducks, at the wintering area, is a response to the winter requirements necessary in large part for their survival (Tamisier and Dehorter 1999). Several winter bird surveys have provided up-to-date figures with rising population trends for the Algerian populations of the Shelduck. In 1971, a winter census conducted in 13 sites of the Oum-El-Bouaghi wetland complex estimated Shelduck population at 1100-1500 individuals (Johnson and Hafner 1972). Next censuses indicated that Shelduck population size is much larger as it was estimated to reach on average 4000 individuals per site, i.e. an estimate which varies between 1000 and 7500 individuals per site (Walmsley 1986).

The trend of wintering waterbird populations in Sabkha Djendli is similar to that observed in adjacent lakes in northeastern Algeria. In fact, several thousand birds are winter migrants at the wetland complex of the wilaya of Oum-El-Bouaghi, where the Shelduck is the most represented Anatidae in this region (Chown and Linsley 1994; Boulkhssaim et al. 2006). This was confirmed with population estimates carried out in early winter of 2004/2005, where Shelduck populations totaled 68,000 wintering individuals in the same region (Boulkhssaim 2008). This study indicates that intermittent and shallow salt lakes of the Hauts Plateaux region in Algeria provide important wintering habitats for the Shelduck and other Anatidae.

\section{Behavioral time budget}

The Shelduck exhibited various behaviors (feeding, loafing, courtship, flying, swimming, etc.) in response to its daily needs during wintering (Baldassarre and Bolen 2006). These activities are subject to temporal variations that follow changes in the numbers of foraging 


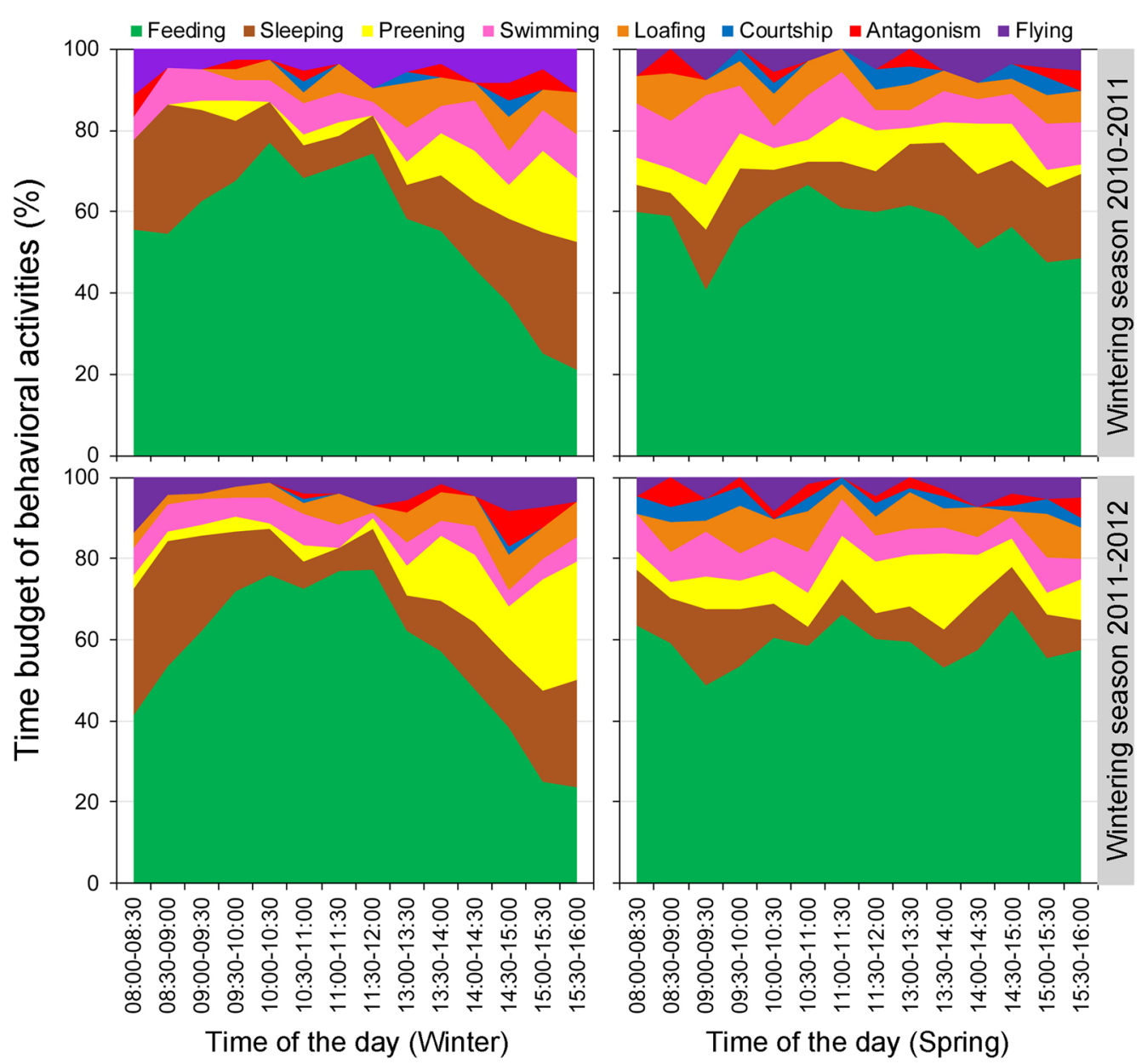

Fig. 6 Variation in diurnal activities of Shelducks following half-hours of the day for the two season (winter and spring) at Sabkha Djendli (Northeastern Algeria) during two wintering seasons 2010-2011 and 2011-2012

conspecifics. Among all the diurnal activities surveyed in the current study, feeding was dominant throughout the wintering season; it is followed by sleeping, then preening and swimming. This specific pattern of diurnal activities observed in Sabkha Djendli is similar to time budgets of the species wintering in neighboring wetlands and Ramsar sites in northeastern (Boulkhssaim 2008; Bezzalla et al. 2019b).

Feeding activity in the Shelduck is both diurnal and nocturnal, where Shelducks feed much more in shallower water and at the edges of salt lakes than in deep water (Boulkhssaim 2008; Bezzalla et al. 2019b). During the period from mid-winter to late winter, feeding activity is associated with sleeping (significantly positive correlation: $r=0.29, p<0.001$, Fig. 7). The time budget of these two activities dominates all other activities. Often Shelducks forage while swimming, whether in shallow water or at the edges of the Sabkha. This is consistent with ecoethological studies on the species in inland wetlands of the Hauts Plateaux region (Boulkhssaim et al. 2006; Bellagoune 2015; Bezzalla et al. 2019b). Foraging and sleeping allow migrant waterbirds to store as much energy in form of adipose deposits in order to match their energetic requirements during the following phenological phases and thus ensure a better breeding success after migration to breeding grounds (Tamisier and Dehorter 1999). As a result, this site represents a key foraging and resting habitat for these duck populations during the wintering season (Bellagoune 2015).

After feeding, activity patterns in Sabkha Djendli are characterized by the predominance of sleeping at the beginning of the wintering season. The increase in time budget assigned to this activity from the beginning of December to mid-January seems to reflect the fact that this behavior allows exhausted and weakened birds following a postnuptial migration to rest and recover energy (Bensizerara 2014). The same findings have been reported on other wetlands in northeastern Algeria 
Table 2 Nested ANOVAs testing the variation of diurnal activities of the Shelduck wintering in Sabkha Djendli in northeastern Algeria across a range of temporal scales

\begin{tabular}{|c|c|c|c|c|c|c|c|c|c|c|c|c|c|}
\hline \multirow[t]{2}{*}{ Time variations } & \multirow[t]{2}{*}{ df } & \multicolumn{3}{|c|}{ Feeding } & \multicolumn{3}{|c|}{ Sleeping } & \multicolumn{3}{|c|}{ Preening } & \multicolumn{3}{|c|}{ Swimming } \\
\hline & & MS & $F$ & $p$ & MS & $F$ & $p$ & MS & $F$ & $p$ & MS & $F$ & $p$ \\
\hline Year (YY) & 1 & 7757 & 87.6 & $<0.001$ & 196.8 & 27.9 & $<0.001$ & 702.0 & 215.5 & $<0.001$ & 21.5 & 10.4 & 0.002 \\
\hline Season (SS) & 1 & 4786 & 54.1 & $<0.001$ & 707.4 & 100.3 & $<0.001$ & 9.0 & 2.8 & 0.100 & 6.4 & 3.1 & 0.081 \\
\hline Month (MM) & 3 & 929 & 10.5 & $<0.001$ & 117.0 & 16.6 & $<0.001$ & 208.5 & 64.0 & $<0.001$ & 113.8 & 55.0 & $<0.001$ \\
\hline Day (DD) & 2 & 57 & 0.6 & 0.527 & 95.0 & 13.5 & $<0.001$ & 14.8 & 4.6 & 0.013 & 30.1 & 14.5 & $<0.001$ \\
\hline Semi-hour (SH) & 13 & 1353 & 15.3 & $<0.001$ & 42.2 & 6.0 & $<0.001$ & 79.9 & 24.5 & $<0.001$ & 20.3 & 9.8 & $<0.001$ \\
\hline$Y Y \times S S$ & 1 & 964 & 10.9 & 0.001 & 104.2 & 14.8 & $<0.001$ & 29.5 & 9.1 & 0.003 & 107.1 & 51.7 & $<0.001$ \\
\hline $\mathrm{MM} \times \mathrm{DD}$ & 5 & 570 & 6.4 & $<0.001$ & 121.6 & 17.2 & $<0.001$ & 12.9 & 3.9 & 0.003 & 112.7 & 54.4 & $<0.001$ \\
\hline $\mathrm{YY} \times \mathrm{SS} \times \mathrm{MM}$ & 2 & 933 & 10.5 & $<0.001$ & 68.9 & 9.8 & $<0.001$ & 9.2 & 2.8 & 0.064 & 51.6 & 24.9 & $<0.001$ \\
\hline $\mathrm{MM} \times \mathrm{DD} \times \mathrm{SH}$ & 143 & 123 & 1.4 & 0.038 & 12.6 & 1.8 & $<0.001$ & 6.7 & 2.1 & $<0.001$ & 3.6 & 1.8 & 0.001 \\
\hline Residuals & 108 & 89 & & & 7.1 & & & 3.3 & & & 2.1 & & \\
\hline \multirow[t]{2}{*}{ Time variations } & \multirow[t]{2}{*}{ df } & \multicolumn{3}{|c|}{ Loafing } & \multicolumn{3}{|c|}{ Courtship } & \multicolumn{3}{|c|}{ Antagonism } & \multicolumn{3}{|l|}{ Flying } \\
\hline & & MS & $F$ & $p$ & MS & $F$ & $p$ & MS & $F$ & $p$ & MS & $F$ & $p$ \\
\hline Year (YY) & 1 & 70.9 & 77.2 & $<0.001$ & 0.0 & 0.0 & 0.999 & 1.3 & 2.3 & 0.133 & 42.4 & 48.1 & $<0.001$ \\
\hline Season (SS) & 1 & 5.5 & 6.0 & 0.016 & 15.1 & 53.5 & $<0.001$ & 0.0 & 0.0 & 0.914 & 58.5 & 66.3 & $<0.001$ \\
\hline Month (MM) & 3 & 45.2 & 49.3 & $<0.001$ & 3.8 & 13.4 & $<0.001$ & 1.3 & 2.3 & 0.079 & 14.0 & 15.8 & $<0.001$ \\
\hline Day (DD) & 2 & 12.3 & 13.4 & $<0.001$ & 0.1 & 0.3 & 0.751 & 0.0 & 0.0 & 0.959 & 4.7 & 5.3 & 0.006 \\
\hline Semi-hour (SH) & 13 & 14.8 & 16.1 & $<0.001$ & 3.6 & 12.6 & $<0.001$ & 6.5 & 11.3 & $<0.001$ & 6.4 & 7.3 & $<0.001$ \\
\hline$Y Y \times S S$ & 1 & 2.6 & 2.8 & 0.095 & 0.5 & 1.8 & 0.184 & 0.3 & 0.6 & 0.442 & 6.0 & 6.8 & 0.011 \\
\hline $\mathrm{MM} \times \mathrm{DD}$ & 5 & 2.3 & 2.5 & 0.032 & 1.2 & 4.2 & 0.001 & 1.3 & 2.3 & 0.051 & 4.0 & 4.5 & $<0.001$ \\
\hline $\mathrm{YY} \times \mathrm{SS} \times \mathrm{MM}$ & 2 & 4.6 & 5.0 & 0.009 & 1.6 & 5.6 & 0.005 & 0.8 & 1.3 & 0.268 & 0.4 & 0.4 & 0.655 \\
\hline $\mathrm{MM} \times \mathrm{DD} \times \mathrm{SH}$ & 143 & 3.7 & 4.0 & $<0.001$ & 0.9 & 3.1 & $<0.001$ & 1.3 & 2.2 & $<0.001$ & 4.7 & 5.3 & $<0.001$ \\
\hline Residuals & 108 & 0.9 & & & 0.3 & & & 0.6 & & & 0.9 & & \\
\hline
\end{tabular}

$d f$ degrees of freedom, MS mean squares, FF-statistics, $p p$-value

(Bezzalla et al. 2019b). This behavior appears to be an adaptive strategy used by this species during early wintering when temperatures are very low, so that sleeping is a way for ducks to reduce energy loss due to cold weather (Bensizerara 2014). Preening was observed consistently from the beginning to the end of the wintering season. In early wintering, the maintenance of plumage in eclipsed individuals is a primary activity noted on the banks and in the water. Preening is known to allow the replacement of damaged feathers in waterbirds that have crossed the Mediterranean to overwinter in North African wetlands (Metallaoui and Houhamdi 2008; Sayoud et al. 2017). Preening and plumage maintenance are very important routine activities in wintering waterbirds as they are involved in thermoregulation. Good plumage maintenance provides good thermal insulation against the outside cold of winter and good insulation against water (Bezzalla et al. 2019b). It also allows the Anatidae to be well prepared for the prenuptial migration (Bouchaala et al. 2017).
Swimming sometimes occupies the free time of this species, and it is also associated with feeding (Correlation: $r=0.32, p<0.001$ ) as some individuals need to move to suitable spots that offer better foraging opportunities such as high quality and abundant food resources, slight competitions, and less predation risk (Boulkhssaim et al. 2006; Bezzalla et al. 2019b). Flying reflects a behavior of escape, avoidance or change of place in order to avoid being predated by terrestrial or aerial predators or to occupy other spots far from other waterbirds, which reduces competitions for food and partner choice/ mate and also antagonistic behavior. The flight is often associated with plumage preening (Correlation: $r=0.30$, $p<0.001)$. In fact, the Shelduck is a very feral species and on the slightest disturbance it flies to other locations quiet and secure. Flying is also a mean to search for suitable feeding habitats such as muddy belts at the edges of Sabkha (Bensizerara 2014). Antagonism is a behavior often due to food competition and/or sexual selection. It is positively correlated with population density (Bezzalla et al. 2019b), while the courtship is linked much more to the nuptial period (Boulkhssaim et al. 2006). 


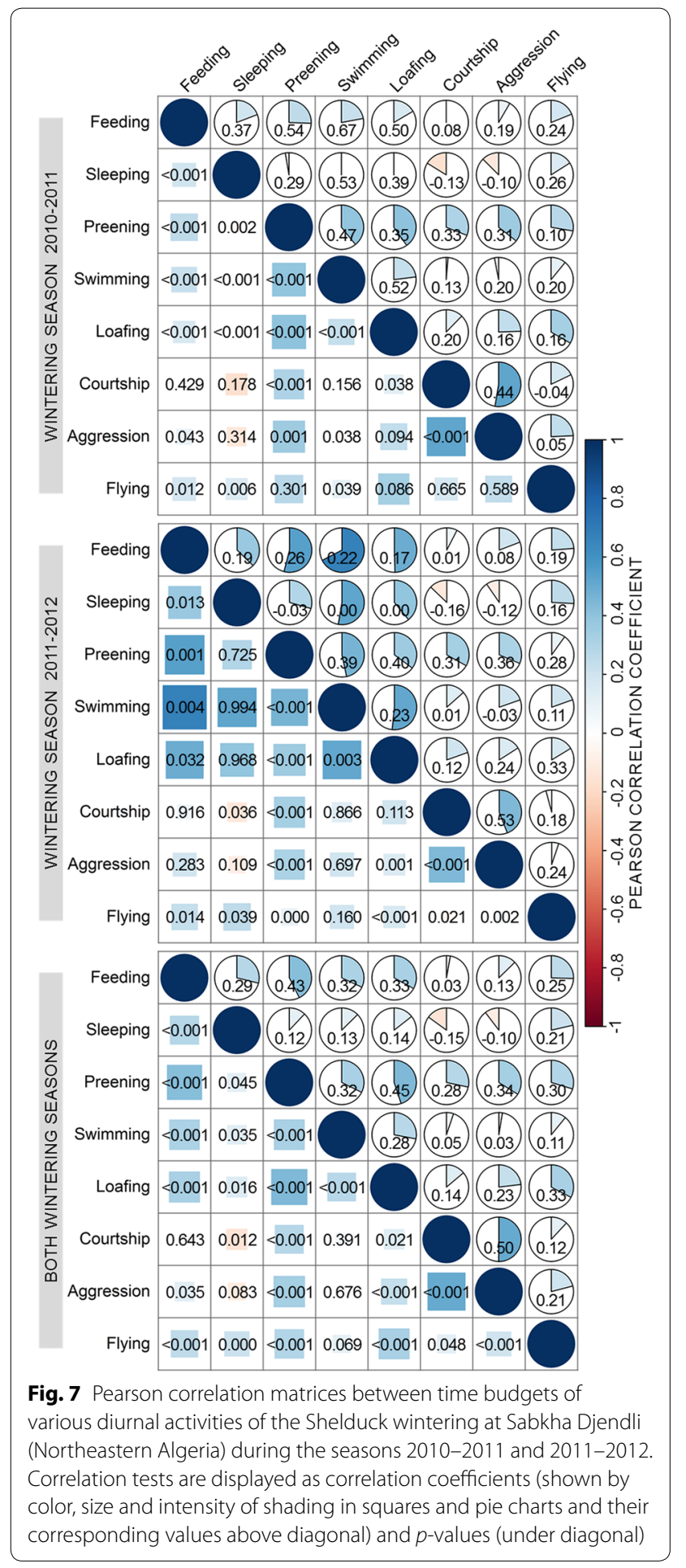

\section{Conclusions}

At Sabkha Djendli, the Shelduck has the status of a wintering migrant that frequents the site from September to April. Local abundance experiences a climax in
Table 3 Summaries of generalized linear models (GLM) testing the effects of Shelduck's population size on weekly variations of diurnal activities of the Shelduck wintering in Sabkha Djendli, northeastern Algeria

\begin{tabular}{|c|c|c|c|c|c|c|}
\hline $\begin{array}{l}\text { Diurnal } \\
\text { activity }\end{array}$ & Variable & Value & $\begin{array}{l}\text { Std. } \\
\text { error }\end{array}$ & $t$-value & $p$-value & Sig. \\
\hline \multirow[t]{2}{*}{ Feeding } & Intercept & 58.417 & 2.053 & 28.46 & $<0.001$ & $* * *$ \\
\hline & Density & 0.001 & 0.001 & 0.86 & 0.405 & ns \\
\hline \multirow[t]{2}{*}{ Sleeping } & Intercept & 12.662 & 1.504 & 8.42 & $<0.001$ & $* * *$ \\
\hline & Density & 0.000 & 0.001 & -0.51 & 0.620 & ns \\
\hline \multirow[t]{2}{*}{ Preening } & Intercept & 7.244 & 1.430 & 5.06 & $<0.001$ & $* * *$ \\
\hline & Density & 0.002 & 0.001 & 2.25 & 0.040 & * \\
\hline \multirow[t]{2}{*}{ Swimming } & Intercept & 9.265 & 1.163 & 7.97 & $<0.001$ & $* * *$ \\
\hline & Density & -0.002 & 0.001 & -2.20 & 0.044 & * \\
\hline \multirow[t]{2}{*}{ Loafing } & Intercept & 6.017 & 0.692 & 8.70 & $<0.001$ & $* * *$ \\
\hline & Density & 0.000 & 0.000 & -0.26 & 0.797 & ns \\
\hline \multirow[t]{2}{*}{ Courtship } & Intercept & 1.255 & 0.507 & 2.48 & 0.026 & $*$ \\
\hline & Density & 0.000 & 0.000 & -0.09 & 0.933 & ns \\
\hline \multirow[t]{2}{*}{ Antagonism } & Intercept & 1.587 & 0.245 & 6.48 & $<0.001$ & $* * *$ \\
\hline & Density & 0.000 & 0.000 & -1.01 & 0.327 & ns \\
\hline \multirow[t]{2}{*}{ Flying } & Intercept & 3.101 & 0.493 & 6.29 & $<0.001$ & $* * *$ \\
\hline & Density & 0.001 & 0.000 & 1.36 & 0.193 & ns \\
\hline
\end{tabular}

Sig. statistical significance

${ }^{* * *} p<0.001,{ }^{*} p \leq 0.05,{ }^{\mathrm{ns}} p>0.05$

mid-winter (December-February) with numbers that can reach up to 2400 individuals in January. Outside the wintering period, the waterbirds including the Shelduck desert the site as the water is drying up. The time budget of daytime activities reveals that Shelducks use the site mainly for feeding (60\%) but also for sleeping (12\%) while keeping swimming (9\%) and preening (8\%), but less importantly for rest loafing (6\%), flying (4\%), courtship (1\%) and antagonistic behavior (1\%). Time allocated to feeding increases in mid-day; meanwhile courtship and antagonistic behaviors were noted. The time spent in sleeping is more important during the morning and evening. With the exception of swimming and preening, the time budget of Shelduck's activities was not densitydependent. The present study indicates that despite the intermittency of Sabkha Djendli and the saline quality of its shallow water, the site is an important overwintering and foraging habitat for the Shelduck. It would be more interesting to conduct a long-term monitoring of anthropogenic disturbances and environmental stresses, such as recurrent drought events inducing shortage in food resources and areas of forging habitats, in order to detect any changes in local abundances, population dynamics and behavior responses of characteristic indicator bird species. 


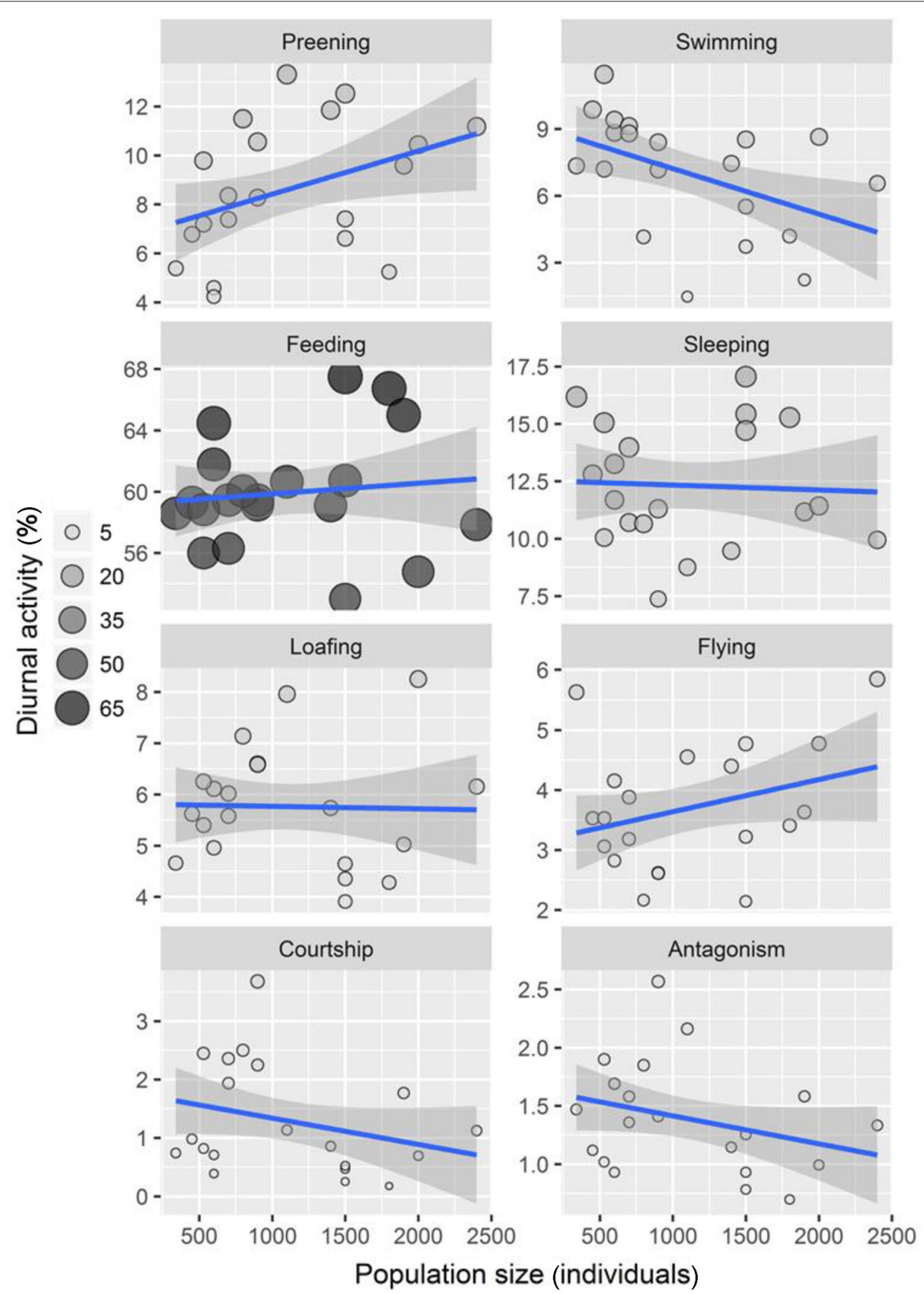

Fig. 8 Relationships between population size and diurnal activities of the Shelduck wintering in Sabkha Djendli (Northeastern Algeria). Size and grey-color intensity of the scattered points are set to values of activity time-budgets. The solid blue lines represent a linear regression with a Gaussian GLM fit and 95\% confidence regions in light grey 


\section{Additional file}

Additional file 1: Table S1. Location and climatic information of Sabkha Djendli in northeastern Algeria. Table S2. Monthly climatic parameters for the region of Sabkha Djendli (Batna Province) in northeastern Algeria. Figure S1. Daily variation of minimum, maximum and average temperatures and monthly precipitation recorded at the region of Sabkha Djendli (Batna, Northeastern Algeria) during the period extending from September 2010 to August 2012.

\section{Authors' contributions}

$\mathrm{DB}$ and $\mathrm{HC}$ conceived and designed the study. DB conducted the experiment and field work. $\mathrm{HC}$ analyzed the data. DB and HC drafted and revised the manuscript. Both authors read and approved the final manuscript.

\section{Author details}

${ }^{1}$ Department of Biology, Faculty of Nature and Life Sciences, University of Abbes Laghrour, 40000 Khenchela, Algeria. ${ }^{2}$ Department of Natural and Life Sciences, Faculty of Exact Sciences and Natural and Life Sciences, University of Tebessa, 12002 Tebessa, Algeria. ${ }^{3}$ Laboratory of Natural Resources and Management of Sensitive Environments 'RNAMS', University of Oum-El-Bouaghi, 04000 Oum-El-Bouaghi, Algeria.

\section{Competing interests}

The authors declare that they have no competing interests.

\section{Availability of data and materials}

The datasets used and/or analyzed during the current study are available from the corresponding author on reasonable request.

\section{Consent for publication}

Not applicable.

\section{Ethics approval and consent to participate}

Not applicable.

\section{Funding}

This study was not funded by any source.

\section{Received: 18 August 2018 Accepted: 11 April 2019}

Published online: 16 April 2019

\section{References}

Aliat T, Kaabeche M, Khomri H, Nouri L, Neffar S, Chenchouni H. A pedological characterisation of some inland wetlands and Ramsar sites in Algeria. Land Degrad Dev. 2016;27:693-705. https://doi.org/10.1002/ldr.2467.

Baldassarre GA, Bolen EG. Waterfowl ecology and management. Malabar: Kreiger Publishing; 2006.

Balla A. Synthèse écologique globale des zones humides d'importance internationale "Sites Ramsar" en Algérie. Ecology Engineer dissertation, University of Batna, Algeria; 2012.

Bellagoune S. Hivernage du Tadorne de Belon Tadorna tadorna (Anatidés) dans la sebkha de Djendli (Batna, Est algérien). Doctoral Thesis. University of Annaba, Algeria; 2015.

Benabderrahmane MC, Chenchouni $\mathrm{H}$. Assessing environmental sensitivity areas to desertification in Eastern Algeria using Mediterranean desertification and land use "MEDALUS" model. Int J Sustain Water Environ Syst. 2010;1:5-10.

Bensizerara D. Ecologie des oiseaux de Sabkhat Djendli. Doctoral Thesis. University of Biskra, Algeria; 2014.

Bensizerara D, Chenchouni H, Si Bachir A, Houhamdi M. Ecological status interactions for assessing bird diversity in relation to a heterogeneous landscape structure. Avian Biol Res. 2013;6:67-77.

Bezzalla A, Houhamdi M, Chenchouni H. Vegetation analysis of Chott Tinsilt and Sebkhet Ezzemoul (two Ramsar sites in Algeria) in relation to soil parameters. In: Chenchouni H, Errami E, Rocha F, et al., editors. Exploring the nexus of geoecology, geography, geoarcheology and geotourism: advances and applications for sustainable development in environmenta sciences and agroforestry research. Cham:Springer; 2019a. p. 38-41. https ://doi.org/10.1007/978-3-030-01683-8_8.

Bezzalla A, Houhamdi M, Chenchouni H. Vegetation analysis of Chott Tinsilt and Sebkhet Ezzemoul (two Ramsar sites in Algeria) in relation to soil parameters. In: Chenchouni H, Errami E, Rocha F, et al., editors. Exploring the nexus of geoecology, geography, geoarcheology and geotourism: advances and applications for sustainable development in environmental sciences and agroforestry research. Cham: Springer; 2019a. p. 38-41.

Bezzalla A, Houhamdi M, Maazi MC, Chenchouni H. Modeling climate influences on population dynamics and diurnal time-budget of the Shelduck (Tadorna tadorna) wintering in Ramsar wetlands of Algeria. Avian Biol Res. 2019b;1:1. https://doi.org/10.1177/1758155919835122.

Bibby CJ, Jones M, Marsden S. Bird surveys. London: Expedition Advisory Centre; 1998.

Bouchaala L, Elafri A, Charchar N, Boukhemza M, Houhamdi M. Wintering behaviour and spatial ecology of Eurasian Wigeon Anas penelope in a coastal Mediterranean wetland complex (Guerbes-Sanhadja) of northeastern Algeria. Avian Biol Res. 2017;10:84-91.

Boulkhssaim M. Ecologie du tadorne dans les zones humides des hautes pleines de l'Est Algérien. Doctoral thesis. University of Annaba, Algeria; 2008.

Boulkhssaim M, Houhandi M, Samraoui B. Status and diurnal behaviour of the Shelduck Tadorna tadorna in the Hauts Plateaux, northeast Algeria. Wildfowl. 2006:56:65-78.

Caraco T. Time budgeting and group size: a theory. Ecology. 1979;60:611-7.

Chenchouni H. Diagnostic écologique d'un site propose Ramsar: Chott Djendli (Batna-Algérie). Engineer Dissertation in Ecology. University of Batna, Algeria; 2007. https://doi.org/10.13140/rg.2.2.30730.67523/1.

Chenchouni H. Diagnostic écologique et évaluation du patrimoine biologique du Lac Ayata (La Vallée de l'Oued Righ: Sahara septentrional algérien). Magiter Dissertation. University of Ouargla, Algeria; 2010a. https://doi. org/10.13140/rg.2.2.18986.62402/1.

Chenchouni H. Drought-induced mass mortality of Atlas cedar forest (Cedrus atlantica) in Algeria. In: Parrota JA, Carr MA, editors. The International Forestry Review, 33th IUFRO World Congress. 23-28/Aug/2010, Seoul, Korea; 2010b.

Chenchouni $\mathrm{H}$. Statuts de protection et de conservation des oiseaux recensés dans les Aurès et ses alentours (nord-est algérien). Proceedings of the international Conference "SIBFA". University of Ouargla, Algeria; 2010c. p. 56-75. https://doi.org/10.13140/2.1.1721.5687.

Chenchouni $\mathrm{H}$. Diversity assessment of vertebrate fauna in a wetland of hot hyperarid lands. Arid Ecosyst. 2012;2:253-63. https://doi.org/10.1134/ S2079096113010022.

Chenchouni H. Contribution à l'étude de la bio-écologie de la Cigogne blanche (Ciconia ciconia) dans la région de Batna (Nord-est algérien). Doctoral thesis, University of Batna 2, Algeria; 2017a.

Chenchouni $\mathrm{H}$. Edaphic factors controlling the distribution of inland halophytes in an ephemeral salt lake "Sabkha ecosystem" at North African semi-arid lands. Sci Total Environ. 2017b;575:660-71. https://doi. org/10.1007/s00484-016-1232-x.

Chenchouni H, Menasria T, Neffar S, Chafaa S, Bradai L, Chaibi R, et al. Spatiotemporal diversity, structure and trophic guilds of insect assemblages in a semi-arid Sabkha ecosystem. PeerJ. 2015;3:e860. https://doi. org/10.7717/peerj.860.

Cherkaoui SI, Selmi S, Hanane S. Ecological factors affecting wetland occupancy by breeding Anatidae in the southwestern Mediterranean. Eco Res. 2017;32:259-69.

Cherry MJ, Barton BT. Effects of wind on predator-prey interactions. Food Webs. 2017;13:92-7.

Chown D, Linsley M. Wetlands in Northern Algeria and Coastal Tunisia. An RSPB Waterfowl survey December 1991 to March 1992. Sandy: Royal Society for the Protection of Birds (RSPB); 1994.

Crawley MJ. The R Book. 2nd ed. Chichester: Wiley; 2013. p. 681-714.

Delany S, Scott S. Waterbird population estimates. Third Edition. Wetlands International Global Series No. 12. Wageningen: Wetlands International; 2002.

Finlayson CM, Everard M, Irvine K, McInnes R, Middleton B, van Dam A, Davidson NC, editors. The wetland book. I: structure and function, management, and methods. Dordrecht: Springer; 2018.

Geraci J, Béchet A, Cézilly F, Ficheux S, Baccetti N, Samraoui B, Wattier R. Greater flamingo colonies around the Mediterranean form a single interbreeding population and share a common history. J Avian Biol. 2012;43:341-54 
Henriksen MV, Hangstrup S, Work F, Krogsgaard MK, Groom GB, Fox AD. Flock distributions of Lesser Flamingos Phoeniconaias minor as potential responses to food abundance-predation risk trade-offs at Kamfers Dam, South Africa. Wildfowl. 2015;65:3-18.

Houhamdi M, Samraoui B. Diurnal time budget of wintering Teal Anas crecca at Lac des Oiseaux, northeast Algeria. Wildfowl. 2001;52:87-96.

Houhamdi M, Samraoui B. Diurnal and nocturnal behaviour of Ferruginous duck Aythya nyroca at Lac des Oiseaux, northern Algeria. Ardeola. 2008:55:59-69.

Isenmann P, Moali A. Les oiseaux d'Algérie-birds of Algeria. Paris: SEOF; 2000 Jensen GH, Tombre IM, Madsen J. Environmental factors affecting numbers of pink-footed geese Anser brachyrhynchus utilising an autumn stopover site. Wildl Biol. 2016;22:183-93.

Johnson AR, Hafner H. Waterfowl census in autumn 1971 on some Tunisian and Algerian wetlands. Int Waterfowl Res Bur Bull. 1972;33:51-62.

Ledant JP, Jacob JP, Jacob P, Malher F, Ochando B, Roche J. Mise à jour de I'avifaune Algérienne. Le Gerfaut. 1981;71:295-398.

Metallaoui S, Houhamdi M. Données préliminaires sur l'avifaune aquatique de la Garaet Hadj-Tahar (Skikda, Nord-Est algérien). ABC Bull. 2008;15:71-6.

Neffar S, Chenchouni H, Si Bachir A. Floristic composition and analysis of spontaneous vegetation of Sabkha Djendli in North-east Algeria. Plant Biosyst. 2016;150:396-403. https://doi.org/10.1080/11263504.2013.810181.

Oswald SA, Nisbet IC, Chiaradia A, Arnold JM. FlexParamCurve: R package for flexible fitting of nonlinear parametric curves. Methods Ecol Evol. 2012;3:1073-7.

Öztürk M, Böer B, Barth HJ, Breckle SW, Clüsener Godt M, Khan MA. Sabkha ecosystems: volume III: Africa and Southern Europe. Dordrecht: Springer; 2011
Paracuellos M. How can habitat selection affect the use of a wetland complex by waterbirds? Biodivers Conserv. 2006;15:4569-82.

Paulus SL. Time-activity budgets of nonbreeding Anatidae: a review. In: Weller MW, editor. Waterfowl in winter. Mineapolis: University of Minnesota Press; 1988. p. 135-52.

R Core Team. R: a language and environment for statistical computing. R Foundation for Statistical Computing, Vienna, Austria; 2018. http://www.Rproject.org/. Accessed 20 July 2018.

Samraoui B, Samraoui F. An ornithological survey of Algerian wetlands: important Bird Areas, Ramsar sites and threatened species. Wildfowl. 2008;58:71-96.

Sayoud MS, Salhi H, Chalabi B, Allali A, Dakki M, Qninba A, et al. The first coordinated trans-North African mid-winter waterbird census: the contribution of the International Waterbird Census to the conservation of waterbirds and wetlands at a biogeographical level. Biol Conserv. 2017;206:11-20.

Tamisier A, Dehorter O. Camargue, Canards et Foulques. Fonctionnement d'un prestigieux quartier d'hiver. Nîmes: Centre Ornithologique du Gard; 1999.

Walmsley JG. Wintering Shelduk Tadorna tadorna in the West Mediterranean. Supplemento Ricerche di Biologia della Selvaggina. 1986;10:339-51.

Wetlands International. Waterbird population estimates. Fifth Edition. Summary Report. Wageningen, The Netherlands: Wetlands International; 2012. http://www.wetlands.org/download/2947/. Accessed 20 July 2018.

Xu F, Liu G, Si Y. Local temperature and El Niño Southern Oscillation influence migration phenology of East Asian migratory waterbirds wintering in Poyang, China. Integr Zool. 2017;12:303-17.
Ready to submit your research? Choose BMC and benefit from:

- fast, convenient online submission

- thorough peer review by experienced researchers in your field

- rapid publication on acceptance

- support for research data, including large and complex data types

- gold Open Access which fosters wider collaboration and increased citations

- maximum visibility for your research: over 100M website views per year

At BMC, research is always in progress.

Learn more biomedcentral.com/submissions 